Kalpa Publications in Civil Engineering
Volume 1, 2017, Pages 363-368
ICRISET2017. International Conference on Re-
search and Innovations in Science, Engineering
\&Technology. Selected papers in Civil Engineering $\quad \mathrm{kaLpo}$

\title{
Vibration Control of Building Subjected to Harmonic Excitation
}

\author{
Narayan Makwana ${ }^{1}$, Snehal V. Mevada ${ }^{2}$ and Vishal B. Patel ${ }^{3}$ \\ ${ }^{1}$ Research Scholar, Structural Engineering Department, BVM-VVNagar, Anand \\ ${ }^{2}$ Assistant Professor, Structural Engineering Department, BVM-VVNagar, Anand \\ ${ }^{3}$ Assistant Professor, Structural Engineering Department, BVM-VVNagar, Anand
}

\begin{abstract}
This paper includes the study of behavior of a single degree of freedom system with viscous dampers subjected to harmonic excitation. In this study one story building is considered. The mathematical model of building subjected to harmonic excitation is obtained and its solution is obtained by state space method. The viscous damper is considered for the building with different percentage of damping. The response of building under resonance and non-resonance condition is obtained and it is observed that it can be significantly reduced by installing viscous damper. It is further observed that the linear viscous damper is more effective in reducing the responses for resonance case.
\end{abstract}

\section{Introduction}

To reduce structural vibration, various energy dissipating devices are used so that catastrophic structural failure can be prevented and it improves the human comfort. Energy dissipating devices can be used in medium to high rise structures. These control systems also known as the protective system for the structures because they can modify response of system dynamically in an acceptable manner.

To reduce vibration of structures energy imposed by natural disturbances should be dissipated in anyway. By means of plastic deformation, internal stressing and rubbing every structure naturally releases some energy. In addition to the inherent natural damping of structure, to increase the damping, various energy dissipating devices are used. These vibration control methods include four control systems which are listed as the (1) passive control system, (2) active control system, (3) semi-active control system and (4) hybrid control system.

In the past some researchers have studied the harmonic response analysis of structures installed with various dampers. Liao and Lai [1] investigated single degree of freedom isolation system with a Magneto-Rheological fluid damper under the harmonic excitations. It is concluded that

C.D. Modhera, G.J. Joshi, D. Soni, I.N. Patel, A.K. Verma, L.B. Zala, S.D. Dhiman, D.R. Bhatt, J.M. Rathod, B.C. Goradiya, M.S. Holia and D.K. Patel (eds.), ICRISET2017 (Kalpa Publications in Civil Engineering, vol. 1), pp. 363-368 
the semi-active controlled Magneto-Rheological damper can reduce the vibration for various range of frequencies. The behavior of active mass damper and vibration control of the tall buildings under harmonic excitation is studied by Ricciardelli et al. [2]. It was observed that the parameters which was reduced have strong relation with the performance of devices. Eissa et al. [3] studied the vibration control using active control techniques. It was found out that the active control was effective for resonance case. Ervin and Wickert [4] studied the behavior of clamped-clamped beam attached with rigid body subjected to forced vibration with periodic or non-periodic impacts between body and base. The effect of structural asymmetry and eccentricity was studied. Scheller and Starossek [5] presented a versatile active mass damper which can be used for the control of structural vibrations of various excitation sources and observed that the rotor damper reduces the vibrations at low mass ratio.

Based on the brief literature review carried out herein, it is observed that less work has been reported to control the vibration of structures using damper in resonance condition. This paper investigates the behavior of single storey building subjected to harmonic excitation under resonance. The specific objective of the study is to obtain the parameters like displacement and acceleration of the building with viscous damper subjected to harmonic excitations.

\section{Modelling of Viscous Damper}

Figure 1 shows the model of building with object of harmonic excitation and viscous damper.

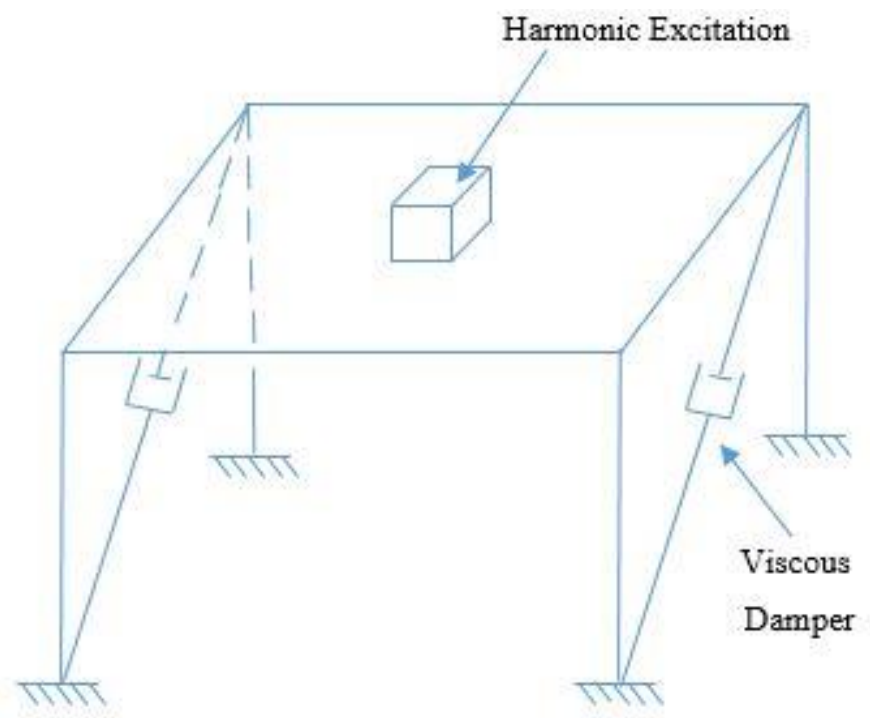

Figure 1. SDOF system with Viscous Damper

A. Equation of Motion

$M \ddot{x}+C \dot{x}+K x+F_{d}=F(t)$

Where, $M=$ Mass,

$C=$ Natural Damping $(5 \%)$,

$K=$ Stiffness,

$F_{d}=C_{d} \dot{x}^{\alpha}$ 


$$
\begin{aligned}
& C_{d}=\text { Damping co-efficient of damper } \\
& \alpha=1, \text { for linear damper } \\
& x=\text { Displacement } \\
& \dot{x}=\text { Velocity } \\
& \ddot{x}=\text { Acceleration, }
\end{aligned}
$$

B. Solution of equation of motion by State Space Method: [6]

$$
\begin{aligned}
& z_{[k+1]}=A_{d} z_{[k]}+B_{d} F_{d_{[k]}}+E_{d} F(t) \\
& \dot{\mathrm{z}}=A z+B F_{d}+E F(t)
\end{aligned}
$$

Where, State vector, $z=\left\{\begin{array}{l}x \\ \dot{x}\end{array}\right\}$,

$$
\begin{aligned}
& \left.\dot{\mathrm{z}}=\begin{array}{c}
\dot{x} \\
\ddot{x}
\end{array}\right\}, \\
& k=\text { time step, } \\
& A_{d}=e^{A \Delta t}, \text { represents the discrete-time system matrix with } \Delta t \text { as the time interval, } \\
& \text { System matrix, } A=\left[\begin{array}{cc}
0 & I \\
-M^{-1} K & -M^{-1} C
\end{array}\right], \\
& \text { Distribution matrix of Control Forces, } B=-\left[\begin{array}{c}
0 \\
M^{-1} \nabla
\end{array}\right], \\
& \text { Distribution matrix of excitations, } E=\left[\begin{array}{l}
0 \\
\Gamma
\end{array}\right], \\
& \nabla=\text { matrix which defines the location of control devices, } \\
& \Gamma=\text { influence co-efficient vector. }
\end{aligned}
$$

\section{Numerical Study}

This numerical study includes behavior of single storey system installed with viscous damper under harmonic excitations. The parameters of building such as displacement and acceleration are obtained by the program developed in the MATLAB. In the present numerical study, four cases have been considered such as (1) building without damper, (2) building with damper (5\% additional damping), (3) building with damper (10\% additional damping) and (4) building with damper (15\% additional damping). The building is installed with two diagonal viscous damper such that both damper introduce the additional damping as mentioned.

Properties of building subjected to harmonic excitation with and without viscous damper:

Single Storey: 
The mass and stiffness of building are adjusted such that time period of building comes out to be 0.9580 seconds

$$
\begin{aligned}
& \text { Mass of motor }=500 \mathrm{~kg} \\
& \text { Radius of unbalanced rotating mass, } r=0.5 \mathrm{~m} \text {, } \\
& \text { Speed of motor, } N=62.6 \mathrm{rpm}, \\
& \text { Forcing frequency, } \omega=6.55 \mathrm{rad} / \mathrm{s}, \\
& \text { Excitation force, } F=10000 \mathrm{~N} .
\end{aligned}
$$

Here the speed of the motor is selected that the frequency of motor matches with the natural frequency of building. The behavior of force with respect to time is shown in Fig. 2.

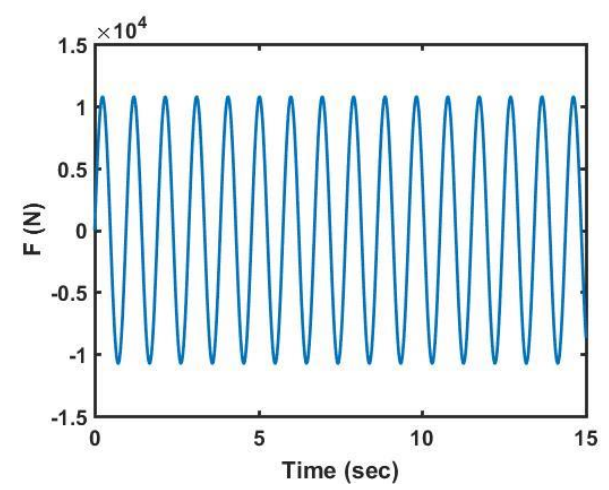

Figure 2: Variation of Applied Harmonic Force

Three different cases have been considered for the building. Case (a) resonance condition $\left(\omega / \omega_{n}=0.99\right.$, speed of motor $\left.62.6 \mathrm{rpm}\right)$, case (b) non-resonance condition $\left(\omega / \omega_{n}=<0.5\right.$, speed of motor $=20 \mathrm{rpm})$ and case $(\mathrm{c})$ non-resonance condition $\left(\omega / \omega_{n}>\sqrt{2}\right.$, speed of motor $\left.=300 \mathrm{rpm}\right)$.

The results of displacement of building in resonance case is shown in Fig. 3. The maximum value of displacement of building for case (1) without damper is $0.0631 \mathrm{~m},(2)$ with damper (5\% additional damping) is $0.0316 \mathrm{~m}$, (3) with damper (10\% additional damping) is $0.0211 \mathrm{~m}$ and (4) with damper ( $15 \%$ additional damping is $0.0158 \mathrm{~m}$; also this result is summarised in the Table-1.

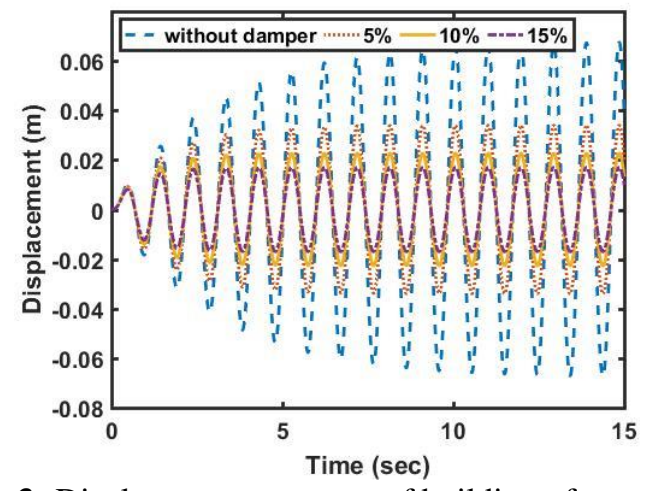

Figure 3: Displacement response of building of resonance case 


\begin{tabular}{|c|c|c|c|}
\hline \multirow{2}{*}{ Case } & \multicolumn{3}{|c|}{ Max. Displacement(m) } \\
\cline { 2 - 4 } & \multirow{2}{*}{$\begin{array}{c}\text { Resonance } \\
\text { case }\end{array}$} & \multicolumn{2}{|c|}{ Non-resonance case } \\
\cline { 3 - 4 } & & $\omega / \omega_{n}<0.5$ & $\omega / \omega_{n}>\sqrt{2}$ \\
\hline Building without Damper & 0.0631 & 0.0088 & 0.0014 \\
\hline Building with Damper (5\%) & 0.0316 & 0.0084 & 0.0014 \\
& $(50 \%)$ & $(5 \%)$ & $(0 \%)$ \\
\hline Building with Damper (10\%) & 0.0211 & 0.008 & 0.0013 \\
& $(66 \%)$ & $(9 \%)$ & $(7 \%)$ \\
\hline Building with Damper (15\%) & 0.0158 & 0.0075 & 0.0013 \\
& $(75 \%)$ & $(15 \%)$ & $(7 \%)$ \\
\hline
\end{tabular}

Table 1: Maximum displacement response for resonance and non-resonance cases

Table 1 shows the maximum displacement response of building under Resonance and NonResonance cases. The values written in the bracket indicates the reduction in percentage with respect to building without damper. It is observed from the table that the controlled and uncontrolled displacement in resonance case is much higher than non-resonance cases. It is further observed that the displacement $\mathrm{n}$ resonance case can be significantly reduced by dampers as compared to nonresonance case. Hence, the dampers are quite effective in reducing the response under resonance case.

Force displacement and force velocity relationship of the viscous damper for building with $10 \%$ damping of resonance case is shown in the Fig. 4. Force-displacement loop represent the energy dissipation capacity and force-velocity loop represent the characteristic of linear viscous damper.

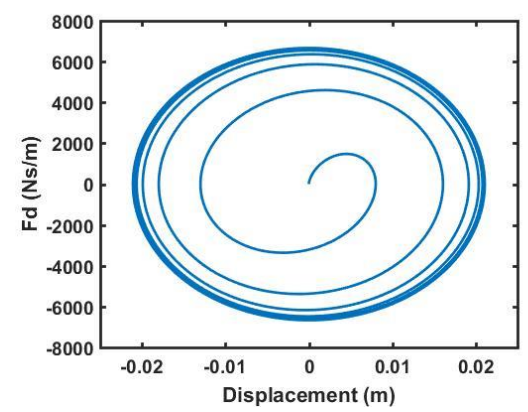

(a) Force - Displacement Relationship

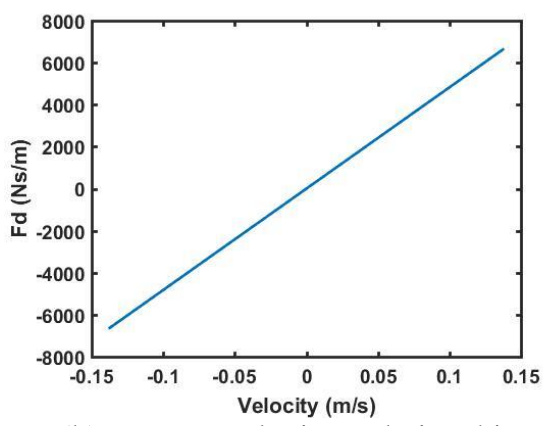

(b) Force - Velocity Relationship

Figure 4: Force displacement \& force velocity Relationship

The displacement and acceleration responses of building in resonance case is evaluated considering various damping percentage and also shown in figures. It is observed from the Figs. 5 and 6 that, the displacement and acceleration reduces significantly with the increase in damping due to viscous damper. 


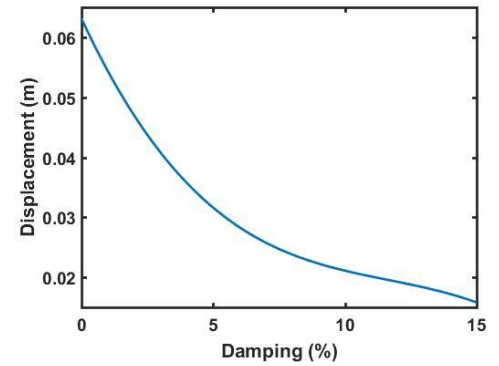

Figure 5: Variation of maximum displacement of building against damping of damper

(for resonance case)

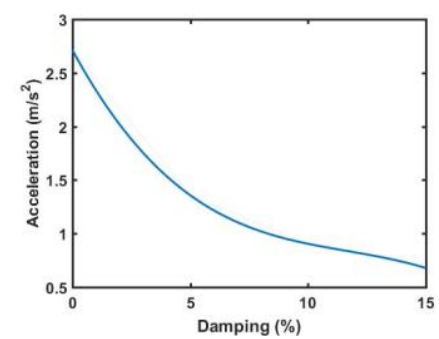

Figure 6: Variation of maximum acceleration of building against damping of damper

(for resonance case)

\section{Conclusion}

The harmonic response analysis of single storey building installed with viscous damper is investigated. Based on the numerical study carried out herein, the following major conclusion can be drawn:

(1) The displacement and acceleration of building in resonance case, reduces significantly with the increase in damping of viscous damper.

(2) The rate of decrease in displacement and acceleration response is significant up to $10 \%$ damping.

(3) The controlled and uncontrolled displacement of building in resonance case is much higher than the corresponding displacement of non-resonance cases, which can be significantly reduce by installing viscous damper.

(4) The hysteresis loop of force and displacement reflect the energy dissipation due to viscous damper and the Force-velocity loop shows the characteristics of linear Viscous Damper.

\section{References}

W H Liao and C Y Lai, "Harmonic analysis of a magnetorheological damper for vibration control" Smart Mater. Struct. 11- 288-296 (2002)

Ricciardelli, F., Pizzimenti, A.D., Mattei, M., "Passive and active mass damper control of the response of tall buildings to wind gustiness." Eng. Struct. 25, 1199-1209 (2003)

M. Eissa, H. S. Bauomy, Y. A. Amer, "Active control of an aircraft tail subject to harmonic excitation" Acta Mech Sin (2007) 23:451-462 (2007)

Elizabeth K. Ervina, J.A. Wickert, "Repetitive impact response of a beam structure subjected to harmonic base excitation” E.K. Ervin, J.A. Wickert / Journal of Sound and Vibration 307-2-19 (2007)

J"orn Scheller, Uwe Starossek, "A versatile active mass damper for structural vibration control" Proceedings of the 8th International Conference on Structural Dynamics, EURODYN 2011, ISBN 978-90-760-1931-4 (2011) Inc.

Gary C. Hart \& Kevin Wong, Structural Dynamics for Structural Engineers, John Wiley \& Sons, 